\title{
Wernicke's Encephalopathy in a Child with Acute Lymphoblastic Leukemia
}

\author{
Akut Lenfoblastik Lösemili Bir Çocuk Hastada Wernicke Ensefalopatisi
}

Hande Kızılocak¹, Gül Nihal Özdemir¹, Gürcan Dikme¹, Zehra Işık Haşıloğlu², Tiraje Celkan¹

1istanbul University Cerrahpaşa Faculty of Medicine, Department of Pediatric Hematology-Oncology, Istanbul, Turkey

2 istanbul University Cerrahpaşa Faculty of Medicine, Department of Radiology, istanbul, Turkey

To the Editor,

We read with great interest the article "A rare complication developing after hematopoietic stem cell transplantation: Wernicke's encephalopathy" by Solmaz et al. [1]. Wernicke's encephalopathy (WE) is an acute syndrome requiring emergent treatment to prevent death and neurologic morbidity [2]. While most often associated with alcoholism, WE also occurs in the setting of prolonged intravenous feeding without adequate thiamine supplementation, prolonged starvation or unbalanced nutrition, gastrointestinal surgery, systemic malignancy, and transplantation [3]. The classic triad of WE includes encephalopathy, oculomotor dysfunction, and gait ataxia. In their article, Solmaz et al. reported a patient who developed WE following hematopoietic stem cell transplantation (HSCT) and they concluded that this was due to prolonged total parental supplementation and lack of thiamine supplementation. The only other suggested cause was the use of busulfan in the conditioning regimen. In the literature there is a link of WE to HSCT, malignancies, or chemotherapies. Here we report a new patient who developed WE during acute lymphoblastic leukemia (ALL) treatment.

A 13-year-old female patient diagnosed with intermediate risk group ALL developed severe neutropenia after a high-dose methotrexate block and oral Purinethol (BFM protocol M). Ceftazidime and fluconazole treatment was started due to fever. After 3 days the patient had poor oral intake and received total parenteral nutrition (TPN) containing protein and dextrose. On the $6^{\text {th }}$ day of TPN she had fever, abdominal pain, nausea, and bilious vomiting. Her abdominal ultrasound revealed typhlitis. Ceftazidime-fluconazole treatment was switched to meropenem and L-amphotericin and oral intake was stopped. On the $8^{\text {th }}$ day of TPN, the patient developed confusion, altered mental status, horizontal nystagmus, and lateral gaze paralysis in the right eye. Her brain computed tomography (CT) was normal. However, brain magnetic resonance imaging (MRI) showed increased signal in the bilateral thalamic pulvinar and mammillary bodies in the axial fluid-attenuated inversion recovery (FLAIR) sequence (Figure 1). These were concluded to be classic findings of WE [4]. Intramuscular thiamine at $200 \mathrm{mg}$ three times a day for the first 3 days ( $600 \mathrm{mg} /$ day total), $100 \mathrm{mg}$ two times a day for the next 3 days (200 mg/day total), and $100 \mathrm{mg}$ thiamine daily for the last 3 days was given. A rapid improvement of neurologic symptoms was observed on the third day of thiamine treatment. The patient's thiamine level was $55 \mathrm{mg} / \mathrm{L}$ and $125 \mathrm{mg} / \mathrm{L}$ before and after the treatment, respectively (normal range: $25-75 \mathrm{mg} / \mathrm{L}$ ). She was discharged from the hospital with good oral intake and normal neurological examination.

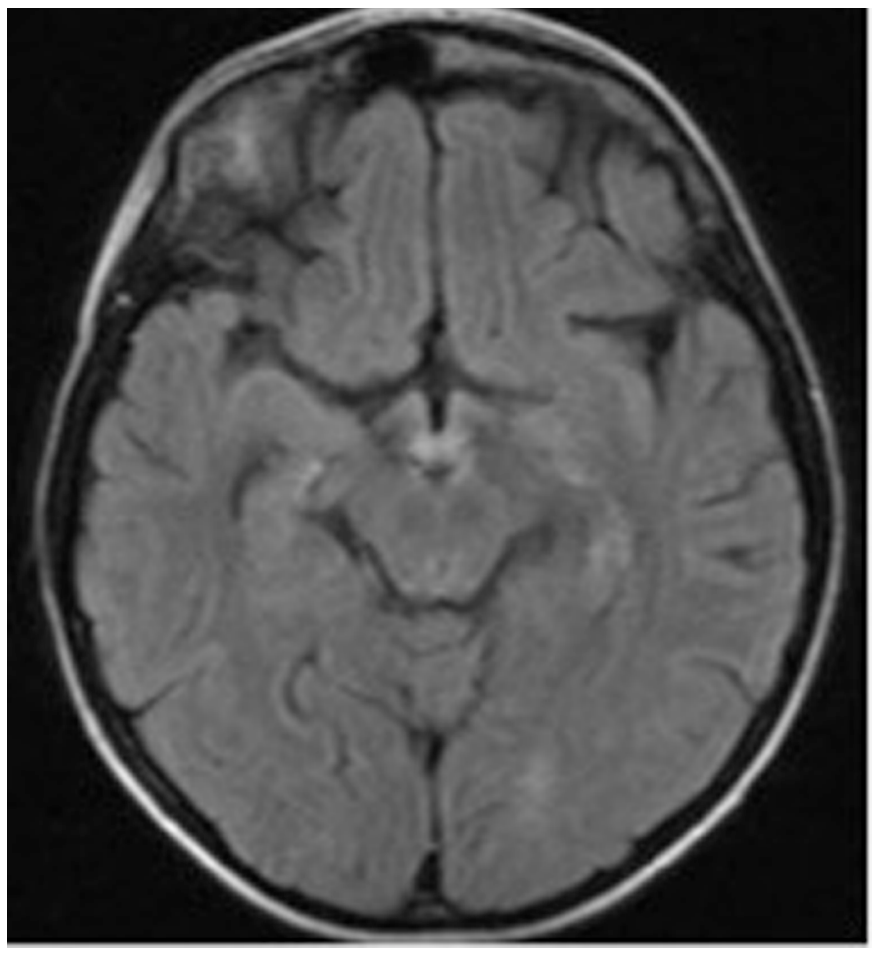

Figure 1. Increased signal in the bilateral thalamic pulvinar and mammillary bodies in the axial fluid-attenuated inversion recovery sequence. 
WE is primarily a clinical diagnosis. Response to treatment may be diagnostic. The sensitivity and specificity of serum thiamine level in symptomatic patients is unclear, as the blood level may not reflect the brain thiamine level. A normal blood thiamine level, as in our patient, does not exclude the possibility of WE with $\mathrm{MRI}$ findings [5]. MRI is more sensitive than CT in WE [6]. In conclusion, all at-risk patients with undiagnosed altered mental status, oculomotor disorders, or ataxia must be evaluated for WE. Further studies are needed for examining the possible role of chemotherapeutics in the development of WE.

Keywords: Wernicke's encephalopathy, Thiamine deficiency, Pediatric leukemia

Anahtar Sözcükler: Wernicke ensefalopatisi, Tiamin eksikliği, Pediatrik lösemi

Conflict of Interest: The authors of this paper have no conflicts of interest, including specific financial interests, relationships, and/or affiliations relevant to the subject matter or materials included.

\section{References}

1. Solmaz $S$, Gereklioğlu Ç, Tan $M$, Demir Ş, Yeral $M$, Korur A, Boğa $C$ Özdoğu H. A rare complication developing after hematopoietic stem cell transplantation: Wernicke's encephalopathy. Turk J Hematol 2015;32:367370.

2. Park SW, Yi YY, Han JW, Kim HD, Lee JS, Kang HC. Wernicke's encephalopathy in a child with high dose thiamine therapy. Korean J Pediatr 2014;57:496499.

3. Parkin AJ, Blunden J, Rees JE, Hunkin NM. Wernicke-Korsakoff syndrome of nonalcoholic origin. Brain Cogn 1991;15:69-82.

4. Beh SC, Frohman TC, Frohman EM. Isolated mammillary body involvement on MRI in Wernicke's encephalopathy. J Neurol Sci 2013;334:172-175.

5. Davies SB, Joshua FF, Zagami AS. Wernicke's encephalopathy in a nonalcoholic patient with a normal blood thiamine level. Med J Aust 2011;194:483-484.

6. Elefante A, Puoti G, Senese R, Coppolo C, Russo C, Tortoro F, de Divitiis O, Brunetti A. Non-alcoholic acute Wernicke's encephalopathy: role of MRI in non typical cases. Eur J Radiol 2012;81:4099-4104.

\title{
Comment: In Response to "Megaloblastic Anemia with Ring Sideroblasts is not Always Myelodysplastic Syndrome"
}

\author{
Yorum: "Halka Sideroblastlı Megaloblastik Anemi Her Zaman Miyelodisplastik Sendrom \\ Olmayabilir"e Yanıt
}

\author{
Smeeta Gajendra \\ Medanta-the Medicity, Department of Pathology and Laboratory Medicine, Gurgaon, India
}

To the Editor,

I read the letter "Megaloblastic Anemia with Ring Sideroblasts is not Always Myelodysplastic Syndrome" by Narang et al., recently published in this journal [1]. The manuscript is well written with a description of a very informative case of megaloblastic anemia with ring sideroblasts in a young female of 18 years old. Ring sideroblasts are associated with abnormal expression of several genes of heme synthesis or mitochondrial iron processing [2]. After exclusion of non-neoplastic causes of ring sideroblasts such as congenital/hereditary sideroblastic anemia and acquired reversible sideroblastic anemia (drugs, toxins, or nutritional deficiency), myelodysplastic syndrome (MDS) can be strongly suspected, particularly in elderly patients. The presence of ring sideroblasts alone is not sufficient for a diagnosis
MDS; the presence of refractory cytopenia(s) is a prerequisite. Refractoriness can only be established after exclusion of secondary causes, most importantly nutritional deficiencies. After that, a complete evaluation of the erythroid, myeloid, and megakaryocytic lineages of bone marrow is essential. At least 15\% ring sideroblasts are required for the diagnosis of MDS with ring sideroblasts (MDS-RS) in cases lacking mutations in the spliceosome gene SF3B1. SF3B1 mutations are found in $60 \%-80 \%$ of patients with refractory anemia with ring sideroblasts (RARS) or RARS with thrombocytosis (RARS-T) and are associated with favorable prognosis [3]. In the recent World Health Organization (WHO) 2016 classification, cases with ring sideroblasts and multilineage dysplasia without excess blasts or isolated del (5q) abnormality are categorized as MDS-RS. Recent 